\title{
Syndromes of abnormal muscular activity: overlap between continuous muscle fibre activity and the stiff
} man syndrome

\author{
GIORGIO VALLI, SERGIO BARBIERI, STEFANO CAPPA, GIULIO PELLEGRINI, \\ GUGLIELMO SCARLATO
}

From the Clinica Neurologica II, Università di Milano, Milan, Italy

SUMMARY Four patients with muscular pain, fasciculations, contractures or cramps are presented.
Evidence of peripheral nerve involvement was revealed by electromyography and nerve
conduction studies. Muscle biopsy showed mild signs of denervation and reinnervation and, at
electron microscopy, dilatations of terminal cisternae were found. All patients showed a
remarkable improvement after therapy with diphenylhydantoin or carbamazepine. These clinical,
neurophysiological and morphological data underline the role of peripheral nerve pathology in
various syndromes of abnormal continuous muscular activity.

Muscular pain, fasciculations, myokymia, contractures and cramps without evidence of long tract involvement frequently has been described in the neurological literature. Two main syndromes are recognised: (1) the syndrome of "continuous muscle fibre activity," first reported by Isaacs, ${ }^{12}$ is characterised by generalised muscular stiffness, fasciculations and clinical but not electrical or mechanical myotonia; (2) the "stiff-man syndrome," first described by Moersh and Woltman, ${ }^{3}$ consists of progressive muscular stiffness in proximal limb muscles with superimposed painful spasms. The two syndromes are differentiated on the basis of the neurophysiological response to procaine nerve block, which does not abolish spontaneous activity in the former but does in the latter. ${ }^{4-6}$ Furthermore, whilst Isaacs' syndrome is improved by diphenylhydantoin, the "stiff-man syndrome" responds to high dosage diazepam. ${ }^{6-11}$

In addition to these two major syndromes, other cases characterised by milder symptoms are encountered in clinical practice, and their classification is difficult. Hudson $e t a^{12}$ defined similar cases as "muscle pain-fasciculation syndrome with myokymia and cramps." A disease with similar features has been described by Jusic et $a l^{13}$ and by Lazaro et al. ${ }^{14}$ The

Address for reprint requests: Dr G Valli, Clinica Neurologica II, Via F. Sforza 35, 20122 Milano, Italy.

pathogenesis of this disorder is unclear but neurophysiological studies indicate a minor impairment of the peripheral nervous system. A peripheral nerve abnormality has also been shown in syndromes of myokymia, fasciculations, spasms and impaired muscular relaxation, sometimes reported as Isaacs' syndrome. ${ }^{15-18}$

We studied four cases with clinical features varying from a syndrome of muscular pain, fasciculations and occasionally cramps to a more severe picture of continuous muscle contractures and painful spasms. Neurophysiological and morphological investigations are suggestive of mild peripheral nerve impairment in these patients.

\section{Case reports}

Case 1. The patient is a 30-year-old woman with two years of progressive muscular stiffness, starting in the hands and forearms and subsequently extending to the legs. She could not relax her handgrip nor make skilled movements with her fingers. On physical examination the limb muscles were prominent, with almost boardlike consistency. Profuse fasciculations were evident, mainly in the shoulder girdle and triceps brachii muscle. Handgrip relaxation was slow as in myotonia; mechanical myotonia was absent. There was no muscle atrophy or weakness. Deep tendon reflexes were decreased or absent. There were no pyramidal or cerebellar signs. Sensory examination was normal. Laboratory examination, including $\mathrm{Na}, \mathrm{K}, \mathrm{P}, \mathrm{Ca}$ and $\mathrm{Mg}$ levels were normal. Cerebrospinal fluid (CSF) examination, EEG, skull and chest radiographs were unremarkable.

Concentric needle electromyography (EMG) showed 
continuous activity in all muscles tested, mainly composed of polyphasic motor unit action potentials (MUAPs), a few of short duration (3-4 ms), mostly of long duration (beyond 15 $\mathrm{ms}$ ), with an amplitude up to $3 \mathrm{mV}$. Occasionally, mainly at needle insertion, MUAPs in doublets and triplets fired briefly. On maximum voluntary effort the recruitment was in a reduced interference pattern: after prolonged effort electrical silence occurred, but spontaneous activity returned after a few seconds (fig 1). Nerve conduction studies, summarised in table 1 , showed a marked difference in motor conduction velocity (MCV) between the right and the left common peroneal nerve. Peripheral nerve block with procaine and intravenous injection of edrophonium chloride $(10 \mathrm{mg})$ and diazepam $(10 \mathrm{mg})$ produced no change, but the muscle abnormalities were abolished by intramuscular procaine; sleep had no effect.

A muscle biopsy from the right tibialis anterior muscle showed only rare atrophic fibres which, with ATPase, were mainly of type 2 . Some "moth eaten" and "central core" fibres were evident with NADH reductase.

Treatment was begun with diphenylhydantoin, $300 \mathrm{mg} /$ day, and later with carbamazepine, $600 \mathrm{mg} /$ day. Both drugs were effective in reducing the rigidity, clinical myotonia and fasciculations. The treatment had to be interrupted two years later, during a pregnancy, and was assumed only irregularly thereafter. On examination five years later the symptoms were greatly reduced. The EMG was normal. Single fibre electromyography (SFEMG) was normal.

Case 2. The patient is a 43-year-old man, with negative familial and past medical history. Three years before admission he started to complain of diffuse paraesthesias and of pain, mainly in the proximal lower limb muscles. Five months later cramps appeared in limb muscles, later spreading to the trunk. Spasms interfered with his night rest and were aggravated by cold, emotional disturbances and
Table 1 Results of nerve conduction studies

\begin{tabular}{|c|c|c|c|c|c|}
\hline Nerve & Case I & Case 2 & Case 3 & Case 4 & $\begin{array}{l}\text { Normal } \\
\text { values }\end{array}$ \\
\hline \multicolumn{6}{|l|}{ Sensory action potentials } \\
\hline $\begin{array}{l}\text { amplitude }(\mu \mathrm{V}) \\
\text { latency to peak }(\mathrm{ms})\end{array}$ & $\begin{array}{l}12 \\
2 \cdot 7\end{array}$ & $\begin{array}{l}8 \\
4 \cdot 5\end{array}$ & $\begin{array}{l}20 \\
2 \cdot 7\end{array}$ & $\begin{array}{l}30 \\
3 \cdot 1\end{array}$ & $\begin{array}{l}\geqslant 8 \\
\leqslant 3 \cdot 4\end{array}$ \\
\hline $\begin{array}{l}\text { Ulnar } \\
\text { amplitude }(\mu \mathrm{V}) \\
\text { latency to peak (ms) }\end{array}$ & $\begin{array}{l}20 \\
2 \cdot 4\end{array}$ & $\begin{array}{l}5 \\
3 \cdot 8\end{array}$ & $\begin{array}{l}12 \\
2.5\end{array}$ & $\begin{array}{l}22 \\
2 \cdot 8\end{array}$ & $\begin{array}{l}\geqslant 6 \\
\leqslant 3 \cdot 1\end{array}$ \\
\hline $\begin{array}{l}\text { Maximal motor conduc } \\
\text { Median }(\mathrm{m} / \mathrm{s}) \\
\text { Peroneal }(\mathrm{m} / \mathrm{s})\end{array}$ & $\begin{array}{l}\text { on veloct } \\
\overline{52} \mathrm{kft} \\
44 \mathrm{righ}\end{array}$ & $\begin{array}{l}\text { ity } \\
\frac{58}{1}\end{array}$ & $\overline{52}$ & $\begin{array}{l}64 \\
48\end{array}$ & $\begin{array}{l}>49 \\
>44\end{array}$ \\
\hline $\begin{array}{l}\text { Tibialis posterior }(\mathrm{m} / \mathrm{s}) \\
\text { F-wave conduction velo } \\
\text { Ulnar } \\
\text { wrist to spinal } \\
\text { cord }(\mathrm{m} / \mathrm{s}) \\
\text { axilla to spinal } \\
\text { cord }(\mathrm{m} / \mathrm{s})\end{array}$ & - & $\begin{array}{l}48 \cdot 5 \\
46\end{array}$ & $\begin{array}{l}55 \\
46\end{array}$ & $\begin{array}{l}64 \\
56\end{array}$ & $\begin{array}{l}>51 \\
>60\end{array}$ \\
\hline
\end{tabular}

meals. In the six months before admission he began to feel stiffness in the lower limb and trunk muscles. Physical examination showed a thin man $(1.67 \mathrm{~m}$ tall, weighing 61 $\mathrm{kg}$ ) in a flexion attitude. There was diffuse muscle atrophy and weakness, more evident in the lower limbs. The lower third of the legs and feet were markedly oedematous. There were diffuse fasciculations and myokymia, sparing only the face. Cramps were frequently visible in the abdominal muscles and in the lower limbs. Deep tendon reflexes were brisk, with the exception of the ankle jerks which were absent. Cutaneous abdominal reflexes were absent and there was no response to plantar cutaneous stimulation bilaterally. Laboratory examinations showed repeatedly elevated values of LDH (up to $350 \mathrm{mU} / \mathrm{l}$ ) and eosinophilia in the leukocyte count. Fasting and post-prandial evaluation

Fig 1 Case 1. EMG of the right tibialis anterior muscle. Electrical silence obtained only after maximum voluntary effort, followed by gradual recurrence of the spontaneous activity. 
of serum $\mathrm{Na}, \mathrm{K}, \mathrm{P}, \mathrm{Ca}, \mathrm{Mg}$ levels were normal. There was a slight increase of gammaglobulins in serum electrophoresis. CSF examination, EEG, chest and skull radiographs and CT scan were unremarkable.

The EMG in the leg muscles showed a continuous dysrhythmic firing of MUAPs (fig 2A), while in the upper limbs and in the thighs fasciculations (often polyphasic) and complex repetitive potentials discharging at high frequency were evident (fig 2B). Polyphasic and long duration potentials were markedly increased, mainly in the lower limb muscles and, on many occasions, involuntary interference patterns corresponding to cramps were recorded. Motor nerve conduction studies (table 1) showed values in the lower normal range. There was a slowing of the F-wave, determined according to Kimura, ${ }^{19}$ in the proximal nerve segment. There also were abnormalities of sensory conduction (table 1). SFEMG in the extensor digitorum communis muscle showed an increase in fibre density $(2 \cdot 2$ per uptake area of the electrode; normal values in this muscle for this age group $1 \cdot 47 \pm 0 \cdot 16$ ). Four abnormal jitters out of 20 potential pairs were found. Intravenous diazepam $(10 \mathrm{mg})$ and sleep had no effect on spontaneous activity. Popliteal

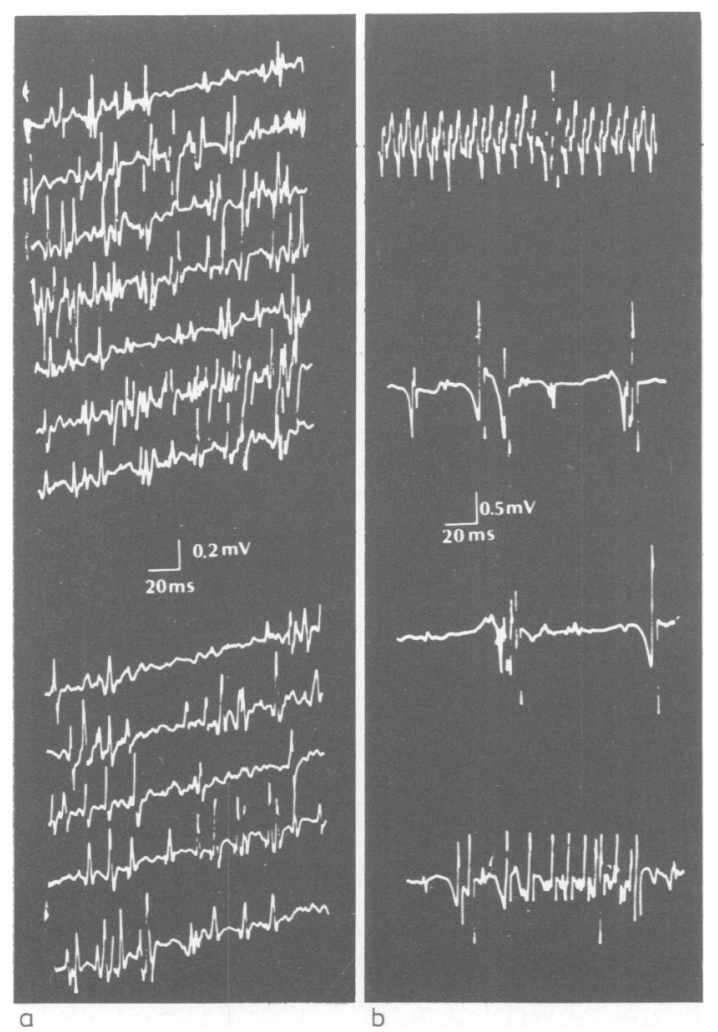

Fig 2 Case 2. A. Left gastrocnemius muscle. Above calibration: spontaneous electrical activity at rest. Below calibration: reduction of the spontaneous activity after procaine infiltration of the nerve. $B$. Vastus medialis muscle. Complex repetitive potentials and fasciculations. nerve block with procaine reduced but did not abolish the spontaneous activity (fig $2 \mathrm{~A}$ ).

A muscle biopsy was performed in the left gemellus lateralis muscle. Variability in fibre size and some atrophic angulated and fusiform fibres were evident (fig 3). With ATPase a clear-cut predominance of type 1 fibres and a tendency toward "type grouping" were found. On electron microscopy there was a dilatation of terminal cisternae and, to a lesser degree, of longitudinal tubules in the sarcoplasmic reticulum (fig 4 ). Irregular papillary projections from the sarcoplasmic and basal membrane, together with deposit of glycogen in subsarcolemmal and interfibrillar spaces were evident. The morphology of the myoneural junction was normal.

A therapeutic trial with diazepam, up to $350 \mathrm{mg} /$ day was carried out. This treatment slightly reduced cramps, without affecting the rigidity. Both symptoms were steadily improved with diphenylhydantoin. An EMG six months later showed a marked reduction of the spontaneous activity. Scanty fibrillation potentials and a few spontaneous potentials, occasionally firing in doublets and multiplets, were found only in the leg muscles and in the biceps brachii.

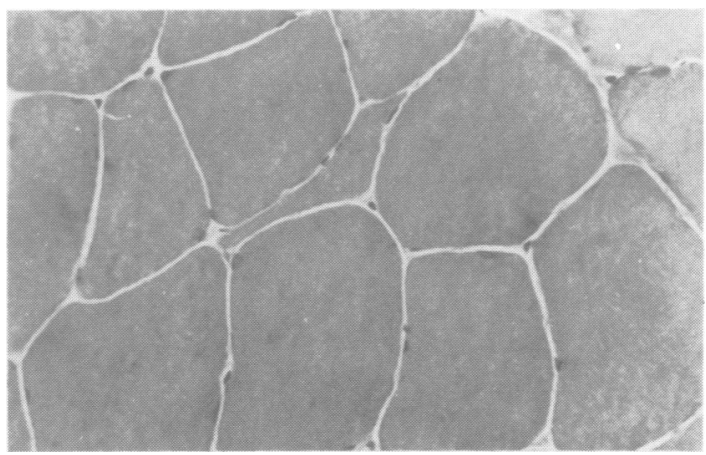

Fig 3 Case 2. Gastrocnemius muscle biopsy. Transverse section. An angulated atrophic muscle fibre suggestive of denervation. Haematoxylin-eosin. $\times 800$

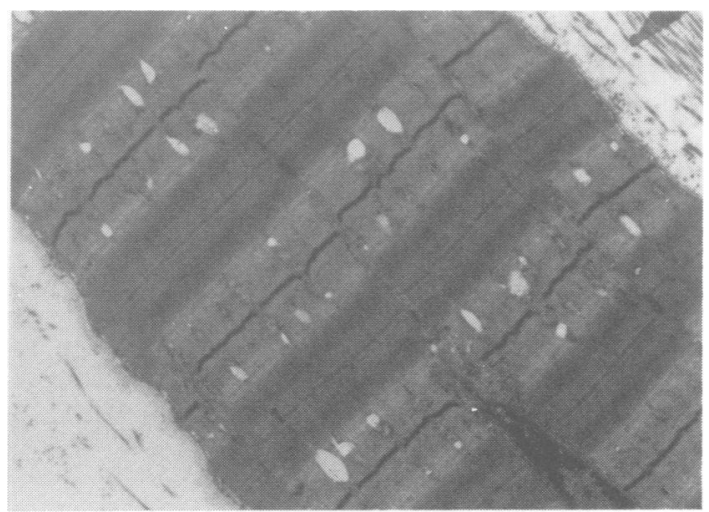

Fig 4 Case 2. Gastrocnemius muscle biopsy. Longitudinal section. Electron micrograph. Dilatation of terminal cisternae. $\times 7000$ 
Nerve conduction studies showed only a slight increase of the latency of the median nerve SAP. The clinical improvement was sufficient to allow the patient to resume his work.

Case 3. This 34-year-old man was well until age 24 , when he began to suffer from anxiety and depression, requiring hospitalisation necessary from time to time. One year before admission he started to complain of muscular pain, mainly in the lower limb and spinal muscles. After a few months, muscle pain and cramps tortured him even at rest, and he noticed widespread twitchings under the skin. Physical examination showed profuse fasciculations in limb and trunk muscles. Cramps were present in the spinal, abdominal and limb muscles. Motor and sensory examination was normal. There was no myotonic response to percussion. Laboratory examination, including serum electrolytes, were normal. There was an increase in IgG in the CSF (6\%, normal values $2 \cdot 3-2 \cdot 7 \%)$. Chest and skull radiographs were normal; on EEG, occasional bursts of theta activity were observed in left fronto-temporal derivations.

On EMG increased insertional activity with high frequency discharges were found. Fibrillation, fasciculations (sometimes polyphasic), doublets and multiplets were abundant (fig 5). Spontaneous interference patterns



Fig 5 Case 3. A. Gastrocnemius medialis muscle. Spontaneous firing of potentials. B. Tibialis anterior muscle. Polyphasic MUAPs of long duration during moderate voluntary effort. C. Vastus medialis. Fasciculations. due to cramps were occasionally recorded and polyphasic potentials of long duration (more than $20 \mathrm{~ms}$ ), with an amplitude up to $6 \mathrm{mV}$, were found mainly in the lower limb muscles. Nerve conduction data (table 1) were normal in distal nerves; the F-wave was slowed in the proximal segment. SFEMG showed a fibre density in the normal range and only one abnormal jitter out of 20 couples. Peroneal nerve block with procaine and intramuscular procaine abolished the spontaneous activity; diazepam (10 mg iv) was ineffective.

Muscle biopsy in the gemellus medialis muscle showed a slight variability in fibre size and shape with histological methods. A clear-cut type 1 predominance was shown with ATPase, as well as type grouping of both fibre types (fig 6). Only rare "core-like" images were present with NADH reductase. On electron microscopy there was dilatation of terminal cisternae and longitudinal tubules of sarcoplasmic reticulum, as well as papillary projections of the membrane. An intramuscular nerve ending was morphologically normal.

A trial with diazepam (100 mg/day) was ineffective. Spasms, mainly in the trunk and abdominal muscles, were reduced with diphenylhydantoin, $300 \mathrm{mg} /$ day and carbamazepine, $600 \mathrm{mg} /$ day.

Case 4. The patient is a 23-year-old Iranian man. He was well until two months before admission, when he began to complain of weakness in the lower limbs, mainly in the calf muscles. After a week he started to complain of deep and burning pain, initially in the lower limbs, later in all body muscles. Sleep was possible only with hypnotics. He noticed profuse and continuous twitching under the skin. Physical examination revealed only profuse fasciculations in the lower limb muscles. Laboratory examination showed only an elevated antistreptolysin titre $(\mathbf{1 0 0 0})$ which returned to normal in two weeks and serum creatine kinase values ranging from 71.5 to $193 \mathrm{IU}$ (normal values less than 70 ). Serum electrolytes were normal. EEG and chest radiographs were normal. CSF examination showed a slight increase in alpha-1 proteins and an increase of beta globulins.

EMG showed the presence of fibrillation and fasciculations in all muscles tested. High frequency discharges (up

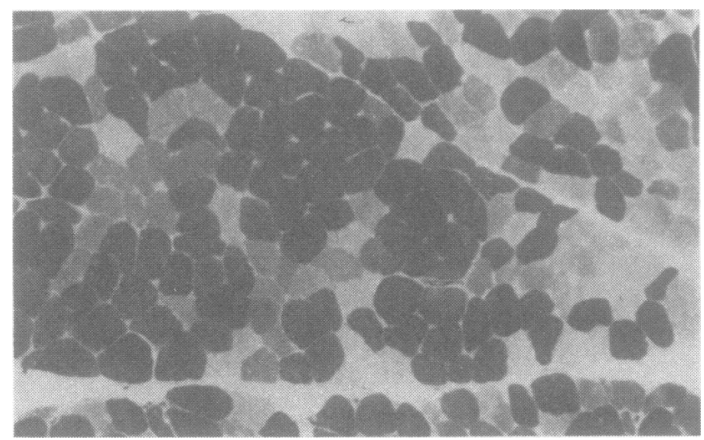

Fig 6 Case 3. Gastrocnemius muscle biopsy. Transverse section. Evidence of type 1 fibre predominance with type 1 grouping. ATPase pH 4.6. $\times 500$ 




Fig 7 Case 4. Vastus lateralis muscle biopsy. Transverse section. Electron micrograph. Dilatation of sarcoplasmic reticulum. $\times 12500$

to $100 \mathrm{~Hz}$ ) were evident only in the first dorsal interosseus muscle. Doublets, triplets and multiplets were seen in the lower limb muscles, while prolonged (more than $15 \mathrm{~ms}$ ) polyphasic MUAPs with an amplitude up to $4 \mathrm{mV}$ were recruited in transitional or reduced interference pattern without increase in the firing rate in all muscle tested. Nerve conduction studies (table 1) showed only a slight proximal slowing of the F-wave. SFEMG was normal. Peroneal nerve block with procaine and sleep did not reduce the spontaneous activity.

Vastus lateralis muscle biopsy showed many scattered pale and necrotic fibres invaded by macrophages. Accumulation of basophilic material, coloured red with Gomori's trichromic stain, was evident in a few fibres. A predominance of type 1 fibres was shown with ATPase. Electron microscopy demonstrated scattered fibres with a markedly dilated sarcoplasmic reticulum and terminal cisternae, without mitochondrial or myofibrillar changes (fig 7). Irregular projections of basement and plasma membrane were also evident.

The patient improved with diphenylhydantoin, $400 \mathrm{mg} /$ day; a marked decrease of leukocyte count led to suspension of this drug, which was replaced with carbamazepine, 800 $\mathrm{mg} /$ day, equally effective and well tolerated. Follow-up EMG showed a marked reduction of spontaneous activity, mainly of fibrillation, while prolonged polyphasic MUAPs were still present. F-wave conduction velocity was $66 \mathrm{~m} / \mathrm{s}$ in the axilla-C7 segment and $67 \mathrm{~m} / \mathrm{s}$ in the wrist-C7 segment.

The main clinical, neurophysiological and morphological features of the four cases are summarised in table 2 .

\section{Discussion}

Until a few years ago cases of muscular pain, fasciculations, contractures and cramps of unknown pathogenesis were generally classified as Isaacs' or "stiff-man" syndrome, according to the predominance of fasciculations and contractures or, respectively, of cramps. The diagnosis was confirmed by pharmacological tests, that is intravenous injection of diazepam and peripheral nerve block with procaine, both being effective in abolishing the spontaneous muscular activity only in "stiff-man syndrome." In many reports, however, the symptomatology has not been as clear-cut as in the original reports. Cases with pain, fasciculations, contractures and cramps occurring together have been described. ${ }^{61820-22}$

Among our patients, case 1 fits well with the clinical syndrome described by Isaacs, ${ }^{12}$ while case 2 is similar to the patient of Lütschg ${ }^{6}$ with a more complex symptomatology and diminished but not abolished spontaneous muscular activity after peripheral nerve

Table 2 Summary of clinical, neurophysiological and morphological data

\begin{tabular}{|c|c|c|c|c|}
\hline & Case I & Case 2 & Case 3 & Case 4 \\
\hline $\begin{array}{l}\text { Age (years), sex } \\
\text { Fasciculations and myokymia } \\
\text { Cramps } \\
\text { Rigidity } \\
\text { Muscle hypotrophy } \\
\text { Response to diazepam therapy } \\
\text { Response to CBZ or DPH therapy } \\
\text { Continuously activated MUAPs } \\
\text { Polyphasic and prolonged MUAPs } \\
\text { Fibrillation } \\
\text { Fasciculations and multiplets } \\
\text { EMG activity due to cramps } \\
\text { Response to Diazepam (10 mg iv) } \\
\text { Response to procaine nerve block } \\
\text { Angulated and atrophic fibres } \\
\text { Fibre necrosis } \\
\text { Type } 1 \text { predominance } \\
\text { "Type grouping" (I and II) } \\
\text { "Moth-eaten" fibres } \\
\text { "Core-like" fibres } \\
\text { Dilatation of cisternae and longitudinal } \\
\text { tubules }\end{array}$ & $\begin{array}{l}\text { 30, F } \\
\text { present } \\
\text { absent } \\
\text { only distal } \\
\text { absent } \\
\text { good } \\
\text { present } \\
\text { present } \\
\text { absent } \\
\text { present } \\
\text { absent } \\
\text { no effect } \\
\text { no effect } \\
\text { present } \\
\text { absent } \\
\text { present } \\
\text { absent } \\
\text { present } \\
\text { present }\end{array}$ & $\begin{array}{l}\text { 43, M } \\
\text { present } \\
\text { present } \\
\text { generalised } \\
\text { legs } \\
\text { slight } \\
\text { good } \\
\text { present } \\
\text { present } \\
\text { present } \\
\text { present } \\
\text { present } \\
\text { no effect } \\
\text { partial effect } \\
\text { present } \\
\text { absent } \\
\text { present } \\
\text { present } \\
\text { absent } \\
\text { absent } \\
\text { present }\end{array}$ & $\begin{array}{l}\text { 34, M } \\
\text { present } \\
\text { present } \\
\text { absent } \\
\text { absent } \\
\text { absent } \\
\text { moderate } \\
\text { absent } \\
\text { present } \\
\text { present } \\
\text { present } \\
\text { present } \\
\text { no effect } \\
\text { effective } \\
\text { absent } \\
\text { absent } \\
\text { present } \\
\text { present } \\
\text { absent } \\
\text { present } \\
\text { present }\end{array}$ & $\begin{array}{l}22, M \\
\text { present } \\
\text { absent } \\
\text { absent } \\
\text { absent } \\
\text { good } \\
\text { absent } \\
\text { present } \\
\text { present } \\
\text { present } \\
\text { absent } \\
\text { no effect } \\
\text { no effect } \\
\text { present } \\
\text { present } \\
\text { present } \\
\text { absent } \\
\text { absent } \\
\text { absent } \\
\text { present }\end{array}$ \\
\hline
\end{tabular}

Note: Nerve conduction findings are reported in table 1.

CBZ: carbamazine. DPH: dyphenylhydantoin. 
block with procaine. The main symptoms in cases 3 and 4 were fasciculations and myalgias without rigidity. They resemble the patients described by Hudson as "muscular pain fasciculation syndrome." ${ }^{12}$ Case 3 furthermore shares with the "stiffman syndrome" the profuse cramp activity and the complete effectiveness of procaine nerve block.

The boundaries between the clinical syndromes of continuous spontaneous muscular activity are thus not as clear-cut as assumed in many previous reports. ${ }^{420}$ The result of procaine nerve block has been considered conclusive. A proximal pathogenesis of the spontaneous activity is indicated in the "stiff-man syndrome" in which the block is effective. A distal origin is indicated in Isaacs' syndrome, where the block is ineffective. Wettstein ${ }^{23}$ has shown that in a pathologic process involving the motor neuron, such as amyotrophic lateral sclerosis, fasciculations can originate both proximally and distally. Similarly the results of peripheral nerve block, which was totally effective in one of our cases, partially effective in another one and ineffective in the other two, do not necessarily point to different pathogenetic mechanisms in syndromes of muscular pain and fasciculations. In cases of proximal nerve lesions a dyingback phenomenon can be present with sprouting of collateral branches with an unstable polarisation that can sustain the abnormal activity when the nerve block is proximal to the site of the axon reflexes. ${ }^{24}$

In all our patients there was evidence for a peripheral nerve involvement: prolonged polyphasic potentials found at EMG examination in all cases, prolonged distal sensory latencies in case 2 , and F-wave conduction velocity slower in the proximal segments in the cases tested (in our laboratory the F-wave in normal subjects is faster in the central segment).$^{25}$ No electromyographic signs of myopathy or neuromuscular junction dysfunction were found. SFEMG gave normal jitter in all cases, except case 2, where the slight abnormalities found were compatible with the more severe peripheral nerve involvement.

The muscle biopsies, besides exhibiting slight denervation and reinnervation signs, consistently showed a predominance of type 1 fibres. This could be the expression of prolonged nerve firing and sustained muscle contraction which enhance histochemical transformation from type 2 to type 1 as shown experimentally. ${ }^{26} 27$ The ultrastructural abnormalities (dilated cisternae and tubules) are probably due to similar mechanisms.

The effectiveness of phenytoin treatment in all our patients can probably be ascribed to a stabilising effect of this drug on all neuronal membranes, including the lower motor neuron ${ }^{28}$; carbamazepine, whose mechanism of action is not known, was also effective in our patient.
In conclusion, several clinical, electrophysiological and histological features, shared by the four cases described, underline the role of peripheral nerve damage in syndromes of continuous muscular activity. The findings of normal neuromuscular function and normal morphology of the end-plate region in our cases is in agreement with the normal miniature end-plate potentials and the lack of evidence for a "quantal squander" reported in a case of Isaacs' syndrome. ${ }^{29}$ These data make a pathogenetic lesion in the nerve terminals or in the neuromuscular junction unlikely. Signs of nerve involvement are frequently reported in the literature, ${ }^{12141718}$ and were present in our cases. Damaged nerve fibres can show an abnormal excitability, ${ }^{17}$ possibly due to ephaptic transmission ${ }^{3031}$ or to axonal reflexes. These phenomena could play an important role in the genesis of syndromes of spontaneous muscular activity and pain, although an abnormal influence mediated by spinal interneurons or supraspinal centres cannot be excluded.

This study has been partially supported by a grant from the "Dino Ferrari" Foundation, Maranello, Modena, Italy.

\section{References}

${ }^{1}$ Isaacs $\mathrm{H}$. A syndrome of continuous muscle fibre activity. J Neurol Neurosurg Psychiatry 1961;24:319-25.

${ }^{2}$ Isaacs $\mathrm{H}$. Continuous muscle fibre activity in an Indian male with additional evidence of terminal motor fibre $\rightleftharpoons \underset{\omega}{\infty}$ abnormality. J Neurol Neurosurg Psychiatry 1967; 30:126-33.

${ }^{3}$ Moersh FP, Woltman HW. Progressive, fluctuating muscular rigidity and spasms ("stiff-man syndrome"): report of a case and some other observations in 13 other cases. Proc Mayo Clin 1956;31:421-7.

${ }^{4}$ Gordon EE, Januszko DM, Kaufman L. A critical survey of "stiff-man syndrome." Am J Med 1967;42:582-9.

${ }^{5}$ Isaacs H. Stiff-man syndrome in a black girl. $J$ Neurol Neurosurg Psychiatry 1979;42:988-94.

${ }^{6}$ Lütschg J, Jerusalem F, Ludin HP, Vassella F, Mumenthaler M. The syndrome of continuous muscle fibre activity. Arch Neurol 1978;35:198-205.

${ }^{7}$ Bady B, Giroud PF, Jallade S, Gaillard L. Une observation de pseudomyotonie guérie par la carbamazépine. Rev Neurol (Paris) 1969;120:277-86.

${ }^{8}$ Isaacs $\mathrm{H}$, Heffron JJA. The syndrome of "continuous muscle fibre activity" cured: further studies. J Neurol Neurosurg Psychiatry 1974;37:1231-5.

${ }^{9}$ Howard FM. A new and effective treatment of the "stiffman syndrome": preliminary report. Proc Staff Meet Mayo Clinic 1963;38:203-12.

${ }^{10}$ Olafson RA, Mulder DW, Howard FM. "Stiff-man syndrome": a review of the literature, report of three additional cases and a discussion of pathophysiology and therapy. Mayo Clinic Proc 1964;39:131-43. 
"Schmidt RT, Stahl SM, Spehlman R. A pharmacologic study of "stiff-man syndrome": correlation of clinical symptoms with urinary 3-methoxy 4-hydroxy phenyl glycol excretion. Neurology (Minneap) 1975;25:622-6.

12 Hudson AJ, Brown WF, Gilbert JJ. The muscular painfasciculation syndrome. Neurology (Minneap) 1978; 28:1105-9.

${ }^{13}$ Jusic A, Dogan S, Stojanovic V. Hereditary persistent distal cramps. J Neurol Neurosurg Psychiatry 1972;35:379-84.

${ }^{14}$ Lazaro RP, Rollinson RD, Fenichel GM. Familial cramps and muscle pain. Arch Neurol 1981;38:22-4.

15 Wallis WE, Van Poznack A, Plum F. Generalised muscular stiffness, fasciculation and myokymia of peripheral nerve origin. Arch Neurol 1970;22:430-9.

${ }^{16}$ Welch LH, Appenzeller O, Bicknell SM. Peripheral neuropathy with myokymia, sustained muscular contraction and continuous moto unit activity. Neurology (Minneap) 1972;22:161-9.

${ }^{17}$ Lance JW, Burke D, Pollard J. Hyperexcitability of motor and sensory neurons in neuromyotonia. Ann Neurol 1979;5:523-32.

${ }^{18}$ Lublin FD, Tsairis P, Streletz LJ et al. Myokymia and impaired relaxation with continuous motor unit activity. J Neurol Neurosurg Psychiatry 1979;42:55762.

${ }^{19}$ Kimura J. F-wave velocity in the central segment of the median and ulnar nerves: a study in normal and in Charcot-Marie-Tooth disease. Neurology (Minneap) 1974;24:539-47.

${ }^{20}$ Sigwald J, Guilleminault C. Syndromes de contractures permanentes. Rev. Neurol (Paris) 1971;124:191-212.

${ }^{21}$ Paertanen VSJ, Saninen H, Saska M, Riekkinen P. Electromyographic and nerve conduction findings in a patient with neuromyotonia, normocalecemic tetany and small cell lung cancer. Acta Neurol Scand 1980;61:216-26.

${ }^{22}$ Barron $S$ and Heffner RR. Continuous muscle fibre activity: a case with unusual clinical features. Arch Neurol 1979;36:520-1.

${ }^{23}$ Wettstein A. The origin of fasciculations in motoneurone disease. Ann Neurol 1979;5:295-300.

${ }^{24}$ Cöers C, Telerman Toppet N, Durdu J. Neurogenic benign fasciculations, pseudomyotonia and pseudotetany. Arch Neurol 1981;38:282-6.

${ }^{25}$ Albizzati MG, Bassi S, Passerini D, Crespi V. F-wave velocity in motor neurone disease. Acta Neurol Scand 1976;54:269-74.

${ }^{26}$ Pette D, Staudte HW, Vrbova G. Physiological and biochemical changes induced by long term stimulation of fast muscle. Naturwsch 1970;59:469-73.

${ }^{27}$ Riley DA and Allin EF. The effects of inactivity, programmed stimulation and denervation on the histochemistry of skeletal muscle fibre types. Exp Neurol 1972;40:391-413.

${ }^{28}$ Morrel F, Bradley W, Ptashne M. Effect of diphenylhydantoin on peripheral nerve. Neurology 1958;8:140-4.

${ }^{29}$ Lambert EH. Microelectrode studies of end-plate potentials. American Academy of Neurology, Course 17, April 24-28, 1978.

${ }^{30}$ Seltzer Z, Marshall D. Ephaptic transmission in chronically damaged peripheral nerve. Neurology 1979;29:1061-3.

${ }^{31}$ Tomasulo RA. Aberrant conduction in human peripheral nerves in polyneuropathy: ephaptic transmission? Neurology 1980;30:413-4. 